\title{
Clinical, laboratory and epidemiological aspects of HPV infection in a low-income population from South Bahia, Brazil
}

\author{
S. R. GADELHA ${ }^{1 * \dagger}+$ D. M. V. SOARES-BARRETO ${ }^{1} \dagger$, G. B. $\operatorname{COSTA}^{1,2} \dagger$, \\ V. C. N. LEAL ${ }^{3}$, L. G. S. GOMES ${ }^{1}$, U. R. SANTOS ${ }^{1}$, G. C. S. FERREIRA ${ }^{1}$, \\ L. D. CARVALHO ${ }^{1}$, S. M. V. SORAES-ALMEIDA ${ }^{1}$, M. A. G. MELLO ${ }^{4}$, \\ A. P. M. MARIANO ${ }^{1}$, S. M. B. $\operatorname{SOUSA}^{5}$, A. R. VAGO ${ }^{6}$ AND L. J. MARIN ${ }^{1}$ \\ ${ }^{1}$ Laboratório de Farmacogenômica e Epidemiologia Molecular, Departamento de Ciências Biológicas, \\ Universidade Estadual de Santa Cruz, Ilhéus, Bahia, Brazil \\ ${ }^{2}$ Laboratório de Vírus, Departamento de Microbiologia, Instituto de Ciências Biológicas, \\ Universidade Federal de Minas Gerais, Belo Horizonte, Minas Gerais, Brazil \\ ${ }^{3}$ Laboratório de Imunogenética, Departamento de Imunologia, Instituto de Ciências Biomédicas, \\ Universidade de São Paulo, São Paulo, SP, Brazil \\ ${ }_{5}^{4}$ Faculdade de Ilhéus, Bahia, Brazil \\ ${ }^{5}$ Departamento de Ciências Naturais, Genética Humana e de Populações, Universidade Estadual do Sudoeste da Bahia, \\ Vitória da Conquista, Bahia, Brazil \\ ${ }^{6}$ Departamento de Morfologia, Instituto de Ciências Biológicas, Universidade Federal de Minas Gerais, \\ Belo Horizonte, Minas Gerais, Brazil
}

Received 17 March 2017; Final revision 19 September 2017; Accepted 10 October 2017; first published online 23 November 2017

\section{SUMMARY}

The aim of this study was to determine the prevalence and risk factors for human papillomavirus (HPV) infection in the Southern region of the State of Bahia, evaluating the performance of alternative complementary methods for cervical lesion detection. Cervical samples from women who attended healthcare units were collected and diagnosed by visual inspection, cervical cytology and nested polymerase chain reaction (PCR). Moreover, hemi-nested PCR was performed to detect different HPV genotypes. The prevalence of HPV infection was $47 \cdot 7 \%$, with genotype 16 detected in most cases. Infection was associated with dyspareunia and bleeding $(P<0 \cdot 001$, odds ratio (OR) $5 \cdot 6,95 \%$ confidence interval (CI) $2 \cdot 815-11 \cdot 14)$ and hormonal contraceptive use $(P=0 \cdot 007$, OR $2 \cdot 33,95 \%$ CI $1 \cdot 25-4 \cdot 34)$. There was a positive correlation between positive PCR and positive visual inspection, cervical cytology and symptoms reported. Furthermore, visual inspection was twice as specific, and had a greater positive predictive value than cytology. We showed a high prevalence of HPV infection in Southern Bahia, with HPV 16 being the most common type, and visual inspection being most effective at detecting HPV lesions, corroborating the suggestion that it can be applied in routine gynecologic examinations for low-income populations.

Key words: Cervical cancer screening, high risk HPV types, HPV, low-income population, public health burden, risk factors, visual inspection of the cervix with acetic acid.

\footnotetext{
* Author for correspondence: S. R. Gadelha, Laboratório de Farmacogenômica e Epidemiologia Molecular, Departamento de Ciências Biológicas, Universidade Estadual de Santa Cruz, Campus Soane Nazaré de Andrade - Rodovia Jorge Amado, km 16, Salobrinho, CEP 45662-900, Ilhéus - Bahia, Brazil.

(Email: sandragadelha@hotmail.com)

$\uparrow$ These authors contributed equally to this work
} 


\section{INTRODUCTION}

Human papillomavirus (HPV) is one of the most common sexually transmitted infections in the world $[1,2]$. Approximately $75 \%-80 \%$ of sexually active people become infected at some time in their lives. Condyloma acuminata is the classic clinical manifestation of HPV, which is caused by non-oncogenic or low-risk (LR) subtypes that lead to verrucous lesions [3]. Only a small portion of infections evolve into precursor cancer lesions and these are caused by oncogenic or high risk (HR) types, such as HPV 16 and HPV 18. Moreover, cervical cancer is considered to have a good prognosis if diagnosed and treated early. On the other hand, late diagnosis is the main reason for high mortality rates $[3,4]$.

Cervical cancer is a public health burden, and Latin America is considered to have the fourth highest incidence in the world [3, 5]. Bolivia and Peru appear to exhibit the highest prevalence in Latin America, followed by Brazil [6]. In Brazil, 16340 new cases were expected for 2016, with an estimated risk ratio of $15 \cdot 85$ cases for every 100000 women [7]. Cervical cancer is more incident in the Northern region, followed by the Northeast and Midwest regions. Southeastern and Southern regions correspond with the third and fourth highest incidences, respectively.

The Papanicolaou test was created based on spontaneous or induced exfoliation of normal or pathological cells from the cervix, and used worldwide for screening precursor lesions and cervical cancer [8]. Furthermore, some authors have suggested complementary methods to detect cervical cancer, such as cervical inspection with $5 \%$ acetic acid [9-11]. This technique has been demonstrated useful in low-resource settings, with sensitivity rates ranging from $79 \%$ to $82 \%$, and specificity rates ranging from $91 \%$ to $92 \%[10,12,13]$, and has proven to be safe and cost-effective. Moreover, cervical inspection with $5 \%$ acetic acid helps to reduce false negative results and can be applied when resources are in short supply in health care units [9-11].

Taking into account the high prevalence of HPV in Brazil and its importance to public health, we investigated the prevalence and risk factors for HPV infection in the Southern region of Bahia. In addition, this study represents an opportunity to discuss complementary diagnosis through cervical inspection, since there are few studies with this approach.

\section{METHODS}

\section{Study population}

A cross-sectional study was carried out during April 2011-2012 with women attended at healthcare units in Southern Bahia, in the following cities: Itabuna, Ilhéus, Arataca, Barro Preto, Buerarema and Coaraci. Participants were invited as volunteers and cervical cell samples were collected. Women exhibiting one or more of the following criteria were excluded from the study: (1) history of hysterectomy, (2) vaginal medication use within 15 days prior to collection, (3) treatment of condyloma or intraepithelial lesions, and (4) sexual activity in last 2 days. All participants were submitted to a structured questionnaire to elicit data on demographics and practices considered risk factors for HPV infection. These data were converted to variables and tested for correlations with positive or negative results related to HPV infection.

\section{Diagnostic criteria for visual inspection}

The presence of acetowhite lesions in the transformation zone near the squamocolumnar junction (JEC), 1 min after application of 5\% acetic acid, was considered as a positive result.

\section{Cervical cytology}

Smears were performed and stained by Pap test and classified according to the Bethesda System. Samples showing atypical squamous cells of undetermined significance (ASCUS), typical squamous cells, cannot rule out high-grade squamous intra-epithelial lesions (ASC-H), squamous intraepithelial lesions (SIL) and high grade squamous intraepithelial lesions (HSIL) were considered positive. The samples showing a normal pattern and inflammatory and/or reactive changes were considered negative. All cytological analysis was performed by a certified and trained Pathologist.

\section{Molecular diagnosis}

Cervical cells were stored in saline solution (at $-20^{\circ}$ C) for later DNA extraction with QIAamp DNA Mini Kit (Qiagen Ltd, Crawley, UK). Viral DNA was detected by nested-polymerase chain reaction (PCR) (primers MY09/MY11 followed by primers GP5+/6+), using adapted protocols previously described $[14,15]$. 
Briefly, in the first round reaction, the following reagents were used: $14.65 \mu \mathrm{l}$ of Milli-Q water; $2 \cdot 5 \mu \mathrm{L}$ of $10 \times$ buffer $(500 \mathrm{mM} \mathrm{KCl}$ and $100 \mathrm{mM}$ Tris- $\mathrm{HCl}$ ( $\mathrm{pH} 8.5)$ ); $0.75 \mu \mathrm{l} \mathrm{MgCl}_{2} 50 \mathrm{mM} ; 4 \mu \mathrm{l}$ from the 'pool' of dNTP $(1.25 \mathrm{mM}) ; 0.3 \mu \mathrm{l}$ of MY09 primer $(10 \mathrm{pmol} / \mu \mathrm{l}) ; 0 \cdot 3 \mu \mathrm{l}$ of MY11 primer $(10 \mathrm{pmol} / \mu \mathrm{l})$; $0.5 \mu \mathrm{l}$ Taq polymerase (Invitrogen $\left.{ }^{\circledR}\right)(1 \mathrm{U} / \mu \mathrm{l})$ and $2 \cdot 0 \mu \mathrm{l}$ of the solution containing the DNA sample (final volume of $25 \mu \mathrm{l}$ ). The cycling conditions were: 1 cycle of $1^{\prime}$ at $94^{\circ} \mathrm{C}$ followed by 40 cycles of $1^{\prime}$ at $95^{\circ} \mathrm{C}, 1^{\prime}$ at $55^{\circ} \mathrm{C}$ and $1^{\prime}$ at $72^{\circ} \mathrm{C}$, followed by $10^{\prime}$ at $72{ }^{\circ} \mathrm{C}$ for final extension. In the second round reaction, the following reagents were used: $28.6 \mu \mathrm{l}$ of Milli-Q water; $5 \mu \mathrm{l}$ of $10 \times$ buffer $(500 \mathrm{mM} \mathrm{KCl}$ and $100 \mathrm{mM}$ Tris- $\mathrm{HCl}(\mathrm{pH} 8 \cdot 5)$ ); $1.5 \mu \mathrm{MgCl}_{2} 50 \mathrm{mM}$; $8 \mu \mathrm{l}$ from the 'pool' of dNTP $(1.25 \mathrm{mM}) ; 0.70 \mu \mathrm{l}$ of GP5+ primer $(22.5 \mathrm{pmol} / \mu \mathrm{l}) ; 0.7 \mu \mathrm{l}$ of GP6+ primer $(18.9 \mathrm{pmol} / \mu \mathrm{l}) ; 0.5 \mu \mathrm{l}$ Taq polymerase (Invitrogen ${ }^{\circledR}$ ) $(1 \mathrm{U} / \mu \mathrm{l})$ and $5.0 \mu \mathrm{l}$ of the solution containing the first round (final volume of $50 \mu \mathrm{l}$ ). The cycling conditions were: 1 cycle of $4^{\prime}$ at $94^{\circ} \mathrm{C}$ followed by 40 cycles of $30^{\prime \prime}$ at $94^{\circ} \mathrm{C}, 30^{\prime \prime}$ at $55^{\circ} \mathrm{C}$ and $30^{\prime \prime}$ at $72^{\circ} \mathrm{C}$, followed by $8^{\prime}$ at $72^{\circ} \mathrm{C}$ for final extension. In addition, all PCR positive samples were analyzed for the presence of the following HPV types: 6 and 11 (the most prevalent low risk), and 16, 18, 31, 33, 52 and 58 (the most prevalent HR) as previously described [16].

\section{Statistical analysis}

A bivariate analysis was carried out using Chi-square and Fisher's exact tests with significance level of 5\% $(P \leqslant 0 \cdot 05)$, to determine the association between abnormalities on clinical examination, cytology and HPV infection by nested-PCR, using EPI-INFO software version $7 \cdot 2 \cdot 1 \cdot 0$ (www.cdc.gov/epiinfo), and BioEstat version 5.0. Multivariate logistic regression analyses were performed in order to correlate independent variables with the nested-PCR. Sensitivity, specificity, positive and negative predictive values were calculated for visual inspection testing and cytological examination. The results of the nested-PCR were used as a parameter in order to assess the accuracy of the visual inspection test and the cytological examination.

\section{Ethical considerations}

This study was approved by the Research Ethics Committee of Universidade Estadual de Santa Cruz under registration number 377/14. Informed consent was obtained from all participants. In case of minors, consent was signed by parents or guardians.

\section{RESULTS}

A total of 195 healthy women were enrolled in this study. Demographic characteristics of the participants are presented in Table 1. The median age was $40 \cdot 3$ years (ranging from 17 to 82 years), with most participants over 30-years-old corresponding to $67 \cdot 2 \%$. The majority $(89 \cdot 2 \%)$ made self-reported mixed skin color. Most individuals $(72.7 \%)$ live with an income of less than one minimum Brazilian wage (approximately US\$220), and have an elementary school education or below $(45.6 \%)$. The rate of illiteracy among the participants was $8 \cdot 2 \%$. Behavioral features such as alcohol consumption, smoking habits, and hormonal contraceptive use were reported by few women, whereas most have stable partners and multiparity history (Table 1). No statistical differences were observed when variables listed above were analyzed with positive and negative results for HPV infection.

The prevalence of HPV infection by PCR was $47 \cdot 7 \%$ (95\% CI 40.8-54.7). HPV 16 was the most frequent type found, with a prevalence rate of $29 \%(95 \%$ CI 20.7-38.9). In addition, seven patients were infected with at least two types of HPV; in all such cases, HPV 16 was present. Furthermore, some HPV 16 cases presented normal cytology and had no clinical abnormalities.

Cytological analysis revealed the presence of inflammation in $51.8 \%$, LSIL in $17 \cdot 4 \%$, HSIL in $10 \cdot 8 \%$, ASCUS in $6.2 \%$ and ASC-H in $1.0 \%$ of participants. In addition, $18 \%$ of women with a HSIL cytology diagnosis had negative PCR results. The clinical symptoms reported were dyspareunia and bleeding (15.4\% and $6 \cdot 2 \%$, respectively). A positive correlation of these symptoms was verified for positive PCR $(P=0.003$; OR 2.55 , CI $95 \%$ $1 \cdot 35-4 \cdot 8)$, for cervical cytology $(P<0 \cdot 001$, OR $3 \cdot 32$, 95\% CI $1 \cdot 75-6 \cdot 31)$ and for positive visual inspection test $(P<0 \cdot 001$, OR $5 \cdot 6,95 \%$ CI $2 \cdot 81-$ 11.14) (Table 2). Hormonal contraceptive use was associated with positive visual inspection test results (Table 3 ).

Sensitivity and specificity rates were $70 \%$ and $85 \%$, respectively for visual inspection and $83 \%$ and $40 \%$, respectively for cytology, when compared with PCR results. There was a correlation between positive PCR and positive visual inspection $\left(\chi^{2}=35 \cdot 37 ; P<0 \cdot 001\right)$, 
Table 1. Demographic characteristics and risk factors in women testing positive or negative by PCR for HPV infection in Southern Bahia, Brazil, 2011-2012

\begin{tabular}{|c|c|c|c|c|}
\hline Variables & $\mathrm{HPV}+(\%)$ & $\mathrm{HPV}-(\%)$ & OR & $P$ value* \\
\hline \multicolumn{5}{|l|}{ Age } \\
\hline$\leqslant 30$ & $29(34 \cdot 3)$ & $35(31 \cdot 2)$ & $1 \cdot 15(0 \cdot 63-2 \cdot 1)$ & $0 \cdot 65$ \\
\hline$>30$ & $64(65 \cdot 7)$ & $67(68 \cdot 8)$ & & \\
\hline \multicolumn{5}{|l|}{ Self-reported skin color } \\
\hline White & $10(10 \cdot 8)$ & $15(14 \cdot 7)$ & $0.73(0 \cdot 29-1 \cdot 81)$ & $0 \cdot 5$ \\
\hline Mixed $^{\dagger}$ & $83(89 \cdot 2)$ & $87(85 \cdot 3)$ & & \\
\hline \multicolumn{5}{|l|}{ Income ${ }^{\ddagger}$} \\
\hline$\leqslant 1$ min wage & $65(73 \cdot 0)$ & $76(76 \cdot 0)$ & $1 \cdot 16(0 \cdot 60-2 \cdot 25)$ & $0 \cdot 73$ \\
\hline$>1$ min wage & $24(27 \cdot 0)$ & $24(24 \cdot 0)$ & & \\
\hline \multicolumn{5}{|l|}{ Education level } \\
\hline Elementary school or less & $44(47 \cdot 3)$ & $45(44 \cdot 1)$ & $1.63(0.54-4.87)$ & $0 \cdot 42$ \\
\hline High school or more & $43(46 \cdot 2)$ & $47(46 \cdot 1)$ & $1 \cdot 52(0 \cdot 51-4 \cdot 55)$ & $0 \cdot 58$ \\
\hline Have never gone to school & $6(6 \cdot 5)$ & $10(9 \cdot 8)$ & Reference & $1 \cdot 0$ \\
\hline \multicolumn{5}{|l|}{ Alcohol use } \\
\hline Yes & $25(26 \cdot 9)$ & $30(29 \cdot 4)$ & $1 \cdot 19(0 \cdot 61-2 \cdot 3)$ & $0 \cdot 61$ \\
\hline No & $68(73 \cdot 1)$ & $72(70 \cdot 6)$ & & \\
\hline \multicolumn{5}{|l|}{ Smoking } \\
\hline Yes & $16(17 \cdot 2)$ & $19(18 \cdot 6)$ & $0.94(0 \cdot 42-2 \cdot 09)$ & $0 \cdot 88$ \\
\hline No & $77(82 \cdot 8)$ & $83(81 \cdot 4)$ & & \\
\hline \multicolumn{5}{|l|}{ Hormonal contraceptive use } \\
\hline Yes & $35(37 \cdot 6)$ & $32(31 \cdot 4)$ & $0.68(0 \cdot 35-1 \cdot 32)$ & $0 \cdot 26$ \\
\hline No & $58(62 \cdot 4)$ & $70(68 \cdot 6)$ & & \\
\hline \multicolumn{5}{|l|}{ Stable partner } \\
\hline Yes & $72(77 \cdot 4)$ & $83(81 \cdot 4)$ & $1 \cdot 11(0 \cdot 40-3 \cdot 1)$ & $0 \cdot 83$ \\
\hline No & $21(22 \cdot 6)$ & $19(18 \cdot 6)$ & & \\
\hline \multicolumn{5}{|l|}{ Multiparity history } \\
\hline$\leqslant 2$ & $32(34 \cdot 4)$ & $28(27 \cdot 5)$ & $1.37(0 \cdot 74-2.54)$ & $0 \cdot 34$ \\
\hline$>2$ & $61(65 \cdot 6)$ & $74(72 \cdot 5)$ & & \\
\hline \multicolumn{5}{|l|}{ First intercourse } \\
\hline$\leqslant 15$ years & $45(48 \cdot 4)$ & $59(57 \cdot 8)$ & $0 \cdot 72(0 \cdot 40-1 \cdot 31)$ & $0 \cdot 29$ \\
\hline$\geqslant 16$ years & $48(51 \cdot 6)$ & $43(42 \cdot 2)$ & & \\
\hline \multicolumn{5}{|l|}{ Length of relationship } \\
\hline$\leqslant 1$ year & $32(34 \cdot 4)$ & $28(27 \cdot 5)$ & $1 \cdot 34(0 \cdot 55-3 \cdot 27)$ & $0 \cdot 51$ \\
\hline$\geqslant 2$ years & $61(65 \cdot 6)$ & $74(72 \cdot 5)$ & & \\
\hline \multicolumn{5}{|l|}{ Breast-feeding } \\
\hline Yes & $75(80 \cdot 6)$ & $84(82 \cdot 4)$ & $0.82(0 \cdot 21-3 \cdot 19)$ & $0 \cdot 78$ \\
\hline No & $18(19 \cdot 4)$ & $18(17 \cdot 6)$ & & \\
\hline
\end{tabular}

* Assessed using Pearson's $\chi^{2}$ test.

$\dagger$ This category includes blacks, mulattos and Indians.

$†$ Income value for one minimum Brazilian wage is approximately US\$220.

cervical cytology $\left(\chi^{2}=8 \cdot 58 ; P=0 \cdot 005\right)$, and symptoms reported $\left(\chi^{2}=12 \cdot 05 ; P=0 \cdot 01\right)$ (Table 2$)$.

The cervical lesion screening technique performance is shown in Table 4. Positive and negative probability ratios were performed for the visual inspection test. The indexes were 4.7 and 0.38 , respectively, while the technique's accuracy was $83 \%$. The positive and negative verisimilitude ratio computations for the cervical cytological exam were 1.38 and 0.425 , respectively, and this technique's accuracy was $65 \%$.

\section{DISCUSSION}

HPV infection and cervical cancer are highly prevalent among women worldwide. The HR HPV types (16 and 18, respectively) are the main genotypes implicated in cervical cancer and pre-cancerous lesions, accounting for approximately $70 \%$ of cervical cancers and approximately $50 \%$ of high-grade lesions [17]. The rates in the Latin American population are higher compared with results of the rest of the world [1]. In a recent study, Capote Negrin reported that Bolivia 
Table 2. Prevalence of clinical symptoms and correlations with primary clinical symptoms, pap smear, visual inspection test and PCR, in women from Southern Bahia, Brazil, 2011-2012

\begin{tabular}{llll}
\hline \hline Clinical symptoms & $N$ & $\%$ & \\
\hline $\begin{array}{l}\text { No symptoms referred } \\
\text { Dyspareunia* }\end{array}$ & 137 & $70 \cdot 3$ & \\
$\begin{array}{l}\text { Bleeding } \\
\text { Dyspareunia and }\end{array}$ & 12 & $6 \cdot 2$ & \\
$\begin{array}{l}\text { bleeding } \\
\text { Total }\end{array}$ & 16 & $8 \cdot 1$ & \\
\hline Correlated variables & $\chi^{2}$ & $P$ & Degrees of \\
& & & Freedom \\
\hline $\begin{array}{l}\text { PCR positive } \\
\text { Cervical cytology }\end{array}$ & $8 \cdot 578$ & $0 \cdot 003$ & 1 \\
Visual inspection test & $40 \cdot 743<091$ & $<0.001$ & 15 \\
\hline \hline
\end{tabular}

* Pain during sexual intercourse.

$\dagger$ Bleeding related to coitus.

Table 3. Demographic characteristics and risk factors related to the presence of acetowhite lesions in the transformation zone, in women from Southern Bahia, Brazil, 2011-2012

\begin{tabular}{llll}
\hline \hline Variables & $\begin{array}{l}P \\
\text { value }\end{array}$ & $\begin{array}{l}\text { Odds } \\
\text { Ratio }\end{array}$ & $\begin{array}{l}95 \% \text { Confidence } \\
\text { Interval }\end{array}$ \\
\hline $\begin{array}{l}\text { Hormonal } \\
\text { contraceptive use }\end{array}$ & 0.007 & $2 \cdot 328$ & $1 \cdot 249-4.342$ \\
$\begin{array}{l}\text { Self-reported skin } \\
\text { color }\end{array}$ & 0.090 & 2.979 & $0 \cdot 850-10 \cdot 37$ \\
$\begin{array}{l}\text { Symptoms referred* } \\
\text { Alcohol } \\
\text { consumption }\end{array}$ & 00.001 & 5.601 & $2 \cdot 815-11 \cdot 143$ \\
Multiparity history & 0.060 & 1.744 & $1.035-2.939$ \\
\hline \hline
\end{tabular}

* Bleeding during sexual intercouse and dyspareunia.

exhibits a higher incidence of cervical cancer (50.73\%), compared with Puerto Rico which accounts for the lowest incidence $(9 \cdot 73 \%)$. On the other hand, Brazil appears with an incidence rate of $24.03 \%$ [18].

Notwithstanding in Brazil, the risk ratio for cervical cancer was 15.85 per 100000 women in 2016, in which Bahia is the third highest state in number of cases $(1 \cdot 180$ new cases per 100000 women). São Paulo and Rio de Janeiro have the highest number of cases (4.360 and 1.490 new cases, respectively) [7].

Several studies have been conducted around Brazil. The prevalence rates range from $10 \cdot 5 \%$ to $48 \cdot 6 \%$ [19-27]. In this study, we detected a high prevalence
Table 4. Performance of conventional diagnostic techniques for screening HPV infections compared with the PCR test in women from Southern Bahia, Brazil, 2011-2012

\begin{tabular}{lll}
\hline \hline Performance & Cytology $(\%)$ & Visual inspection test $(\%)$ \\
\hline Sensibility & 83 & 70 \\
Specificity & 40 & 85 \\
PPV & 65 & 83 \\
NPV & 64 & 74 \\
\hline \hline
\end{tabular}

PPV, Positive Predictive Value; NPV, Negative Predictive Value.

of HPV infection in Southern Bahia $(47 \cdot 7 \%, 95 \%$ CI 40.8-54.7), which is similar to the prevalence reported in Rio de Janeiro [27], and higher when compared with other regions including Salvador, the Capital of Bahia State $[23,28]$.

HPV 16 is described as responsible for the majority of HPV-associated cancers [3, 4, 6, 17]. Our results demonstrated that HPV 16 was the most frequent type found in women from South Bahia (29\%, 95\% CI 20.7-38.9), similar with findings reported by Oliveira-Silva in Rio de Janeiro (28\%).

HPV infection is the most important risk factor for cervical cancer development. However, HPV infection itself does not represent a sufficient cause, and several other factors increase the chances of developing cervical cancer, such as young age, co-infections, long-term oral contraceptive use, smoking, immunosuppression, multiparity, and sexual activity markers (high number of sexual partners, young age at sexual debut, and recent new sexual partner) [3, 29-31]. Although it was not found to be a positive correlation with HPV infection and most of the related risk factors listed above (Table 1), the use of hormonal contraceptives was highly associated with the presence of acetowhite lesions (Table 3). Indeed, steroid hormone use (estrogen and progesterone) increase the chances for rapid progression of high-grade squamous intraepithelial lesions, as has already been shown for cervical cancer in other studies [3, 30].

Bleeding after intercourse and dyspareunia were the most reported symptoms, showing a strong correlation with HPV infection (Table 2). Positive PCR was 2.5 times more common with those women suffering from dyspareunia and bleeding (OR 2.55, 95\% CI $2 \cdot 48-2 \cdot 84, P=0 \cdot 003)$. The existence of bleeding is closely related to the presence of high-grade intraepithelial lesions, which can be explained by the high 
degree of cellular modifications. Hence, in the poorest regions, the visual inspection test can be useful for early detection of premalignant and malignant cervical disease, helping decrease postcoital bleeding, and prompting additional evaluation and treatment $[32,33]$.

The incidence rates of cervical cancer have declined over the past three decades in most developing countries, due mainly to prevention programs implemented. Methods that allow early screening are extremely important for defining treatment and containing the infection [3-7]. The high prevalence found in this study could be associated with the combination of different methodologies employed, the sampling number and the sample source (public health units).

Visual inspection tests have been applied as a useful alternative method to cytology, improving cervical lesion screenings, without additional costs [9-11, 34]. In our survey, visual inspection showed a better performance when compared with cervical cytology, as analyzed by positive and negative probability ratios and the technique's accuracy (Table 4). Cervical cytology was more sensitive and most patients with positive cytology had high grade lesions. However, the visual inspection test proved to be twice as specific and obtained a positive predictive value greater than cytology. These data demonstrate that the visual inspection test is, in fact, more likely to point towards HPV infection. As already demonstrated in the literature, sensitivity and specificity rates for detecting HSIL lesions are similar between the colposcopy and the visual inspection test, demonstrating that this alternative method can be useful for low-income populations in poorer regions $[35,36]$. Furthermore, the verisimilitude ratio showed that visual inspection was almost five times more accurate than cytology, decreasing the chances of false-negative results. Additionally, we showed that PCR for detection of HPV infection was strongly related to the positive visual inspection test (OR 7.3, 95\% CI 3.64-14.66, $P<0.001)$, and associated with cervical cytology (ASCUS, ASC-H, LSIL and HSIL; $\chi^{2}=12.053$ and $P=0 \cdot 0001)$.

\section{CONCLUSION}

In conclusion, we found a high prevalence of HPV infection in low-income women in Southern Bahia, with HPV 16 as the most common type. A positive correlation between HPV infection and the use of hormonal contraceptives was found. Moreover, our results corroborate the visual inspection test as a useful tool for cervical cancer screening in areas with limited financial resources. Finally, as HPV constitutes a substantial public health burden, combined alternative conventional methods could provide rapid results, enhancing early cervical cancer prevention, with rapid diagnosis and treatment.

\section{ACKNOWLEDGEMENTS}

We thank undergraduate research students Juliete Costa and João Henrique Fonseca, and also the nurses from the healthcare units for their excellent technical support. We also thank all the volunteers for taking part in this study. This research was supported by Universidade Estadual de Santa Cruz (UESC). There are no competing interests.

\section{REFERENCES}

1. Centers for Disease Control and Prevention (CDC). Genital HPV Infection - Fact Sheet (https://www.cdc. gov/std/hpv/stdfact-hpv.htm). Accessed 28 August 2017.

2. World Health Organization (WHO). Sexually Transmitted Infections (STIs) - Fact Sheet (http://www. who.int/mediacentre/factsheets/fs110/en/). Accessed 28 August 2017.

3. Schiffman M, et al. Carcinogenic human papillomavirus infection. Nature Reviews Disease Primers 2016; 2: 16086.

4. Ting J, et al. Worldwide incidence of cervical lesions: a systematic review. Epidemiology and Infection 2015; 143: $225-241$

5. Murillo R, et al. Cervical cancer in Central and South America: Burden of disease and status of disease control. Cancer Epidemiology 2016; 44: S121-S130.

6. Bosch FX. Eradication of cervical cancer in Latin America. Salud Pública de México 2016; 58: 97-100.

7. Brasil, Ministério da Saúde. Estimativa 2016: incidência de câncer no Brasil/Instituto Nacional de Câncer José Alencar Gomes da Silva. Rio de Janeiro: INCA, 2015.

8. Kulasingam SL, et al. Evaluation of human papillomavirus testing in primary screening for cervical abnormalities: comparison of sensitivity, specificity, and frequency of referral. Journal of American Medical Association 2002; 288: 1749-1757.

9. Sankaranarayanan R, et al. Effect of visual screening on cervical cancer incidence and mortality in Tamil Nadu, India: a cluster-randomised trial. The Lancet 2007; 370: 398-406.

10. Sauvaget C, et al. Accuracy of visual inspection with acetic acid for cervical cancer screening. International Journal of Gynaecology and Obstetrics 2011; 113: 14-24.

11. Misra A, et al. Visual inspection by acetic acid as a tool in screening of cervical cancer in rural areas of Hapur, 
UP. International Journal of Health Sciences and Research 2013; 7: 66-70.

12. Kalgong G, et al. Sensitivity and specificity of visual inspection with acetic acid (VIA) and with lugol iodine (VILI) in the diagnosis of cervical cancer in the Northern Region of Cameroon. International Biological \& Biomedical Journal 2017; 3: 66-72.

13. Mustafa RA, et al. Systematic reviews and metaanalyses of the accuracy of HPV tests, visual inspection with acetic acid, cytology, and colposcopy. International Journal of Gynecology \& Obstetrics 2016; 132: 259-265.

14. Levi JE, et al. High prevalence of human papillomavirus (HPV) infections and high frequency of multiple HPV genotypes in human immunodeficiency virusinfected women in Brazil. Journal of Clinical Microbiology 2002; 40: 3341-3345.

15. de Roda Husman AM, et al. The use of general primers GP5 and GP6 elongated at their 3 ends with adjacent highly conserved sequences improves human papilomavírus detection by PCR. Journal of General Virology 1995; 76: 1057-1062.

16. Yamaguchi A, et al. Detection of human papillomavirus DNA by PCR/microfluorometry for screening of cervical cancer. Clinica Chimica Acta 2002; 318(1-2): 41-49.

17. World Health Organization (WHO). Comprehensive Cervical Cancer Control - A Guide to Essential Practice, 2nd edn. 2014; 364 pages (http://apps.who.int/ iris/bitstream/10665/144785/1/9789241548953_eng.pdf). Accessed 10 March 2017.

18. Capote Negrin LG. Epidemiology of cervical cancer in Latin America. Ecancermedicalscience 2015; 9: 577.

19. de Medeiros Fernandes TA, et al. Human papillomavirus infection in women attended at a cervical cancer screening service in Natal, Brazil. Brazilian Journal of Microbiology 2008; 39: 573-578.

20. Oliveira-Silva M, et al. Human papillomavirus in Brazilian women with and without cervical lesions. Virology Journal 2011; 8: 4.

21. Miranda PM, et al. Human papillomavirus infection in Brazilian women with normal cervical cytology. Genetics and Molecular Research 2012; 11: 1752-1761.

22. Coser J, et al. Prevalence and genotypic diversity of cervical human papillomavirus infection among women from an urban center in Brazil. Genetics and Molecular Research 2013; 12: 4276-4285.

23. Bruno A, et al. Genotype distribution of human papillomavirus in women from the state of Bahia, Brazil. Revista Brasileira de Ginecologia e Obstetricia 2014; 36: $416-422$
24. de Almeida FG, et al. Molecular epidemiology of the human papillomavirus infection in self-collected samples from young women. Journal of Medical Virology 2014; 86: 266-271.

25. de Aguiar SR, et al. Human papillomavirus: prevalence and factors associated in women prisoners population from the Eastern Brazilian Amazon. Journal of Medical Virology 2014; 86: 1528-1533.

26. de Campos KLM, et al. Good agreements between self and clinician-collected specimens for the detection of human papillomavirus in Brazilian patients. Memorias do Instituto Oswaldo Cruz 2014; 109: 352-355.

27. Martins TR, et al. HPV genotype distribution in Brazilian women with and without cervical lesions: correlation to cytological data. Virology Journal 2016; 13: 138

28. Oliveira PM, et al. Prevalence and risk factors for cervical intraepithelial neoplasia in HIV-infected women in Salvador, Bahia, Brazil. Sao Paulo Medical Journal 2010; 128: 197-201.

29. Mzarico E, et al. Relationship between smoking, HPV infection, and risk of cervical cancer. European Journal of Gynaecology and Oncology 2015; 36: 677-680.

30. Chung SH, Franceschi S, Lambert PF. Estrogen and ER- $\alpha$ : culprits in cervical cancer? Trends in Endocrinology and Metabolism 2010; 21: 504-511.

31. Del Río-Ospina L, et al. Multiple high-risk HPV genotypes are grouped by type and are associated with viral load and risk factors. Epidemiology and Infection 2017; 10: 1-12.

32. Tarney CM, Han J. Postcoital bleeding: a review on etiology, diagnosis, and management. Obstetrics and Gynaecology International 2014; 2014: 192087.

33. Khan Z, Appleton F, Turner J. Is cervical intra-epithelial neoplasia symptomatic? Journal of Obstetrics and Gynaecology 2008; 28: 336-337.

34. Aggarwal $\mathbf{P}$, et al. Can visual inspection with acetic acid under magnification substitute colposcopy in detecting cervical intraepithelial neoplasia in low-resource settings? Archives of Gynaecology and Obstetrics 2011; 284: 397-403.

35. Roland KB, et al. Changes in knowledge and beliefs about human papillomavirus and cervical cancer screening intervals in low-income women after an educational intervention. Journal of Primary Care \& Community Health 2016; 7: 88-95.

36. Torre LA, et al. Global cancer in women: burden and trends. Cancer Epidemiology, Biomarkers \& Prevention 2017; 26: 444-457. 